\title{
COVID-19 Infection - the Possibility to Involve Oxygen as Immunogen in the ARDS Determinism (Acute Respiratory Distress Syndrome)
}

\author{
Mihaela GHIMPU*
}

Medically retired clinical immunologist/allergist, lasi, Romania
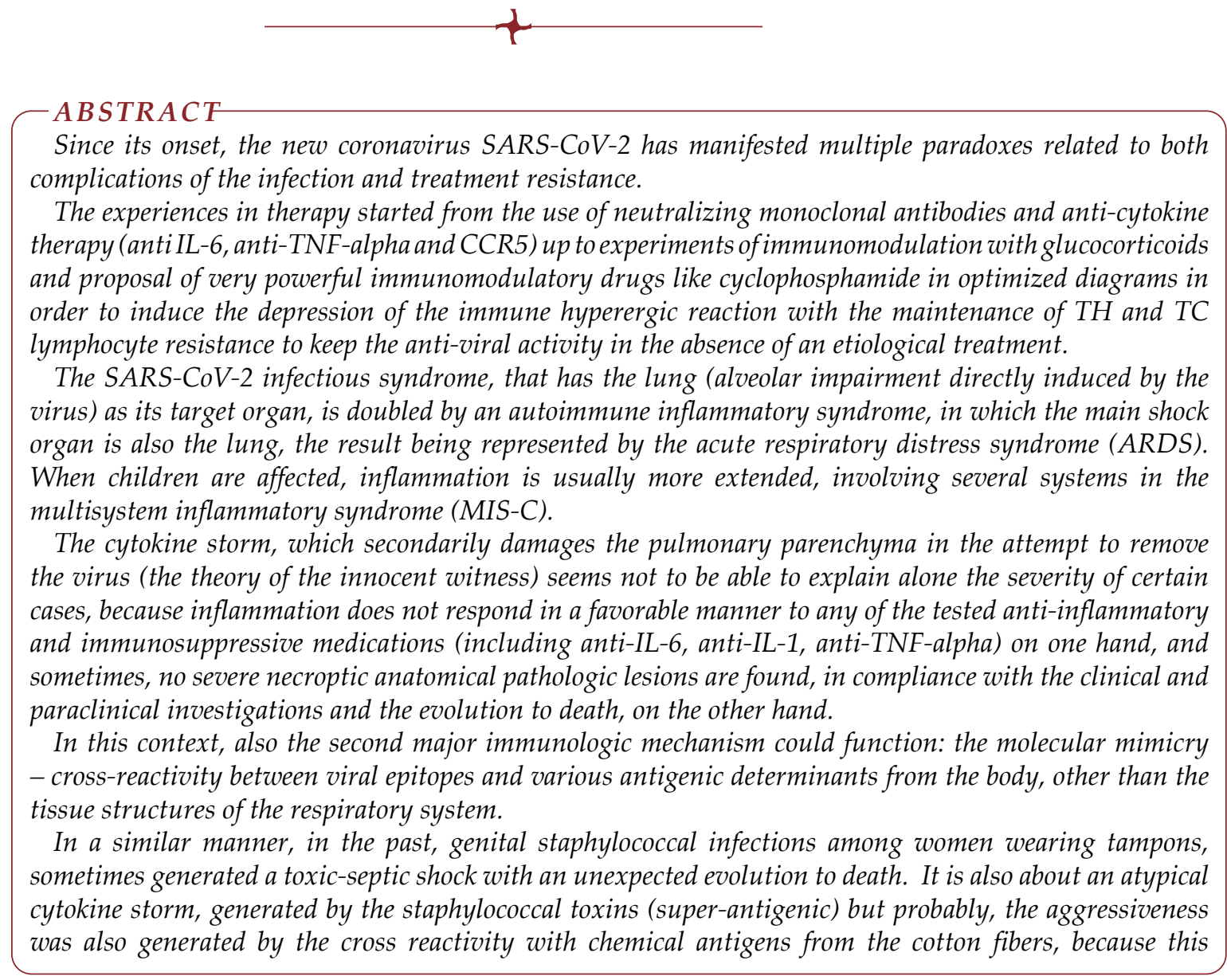

Address for correspondence:

Mihaela Ghimpu

Email:mghimpu10044@gmail.com

Article received on the $28^{\text {th }}$ of June 2021 and accepted for publication on the $23^{\text {rd }}$ of September 2021 
disorder generally appeared among women in the menstrual period, sometimes the local genital infection being minor. Moreover, with the lapse of time, the reaction of shock no longer appeared, probable through the increase of immunologic tolerance to cotton fibers.

In a similar manner, in COVID-19 a reaction of hyper-sensitivity to a gaseous antigen could overlap, considering the decrease of tolerance at the invasive administration of oxygen (the contact with $B A L T$ - the lymphatic system associated to the bronchia, where the resident macrophage is the siderophage) and partial maintenance at the non-invasive administration through mask or extracorporeal, which induces the first contact with the lymphatic elements associated to the oropharyngeal cavity or blood, where the siderophage can no longer be observed. In this context, some adult patients with COVID-19 could manifest an immunologic genetic defect of TS at BALT level, as women with staphylococcal toxic-septic shock had a local defect at the VALT level (lymphatic tissue associated with the genital tract).

In children, the syndrome is rare and more multisystem, which rather suggests the breaking of central tolerance through the lack of intra-thymus or intra-medullary deletion of the auto-reactive clones of (Th TC), while among adults the defect seems to be more peripheral, local, with the involvement of TS and resident macrophages (siderophages). This could explain not only the higher level of severity in elder patients and those with cardiac disorders but also the rarity of the pathology in patients aged under nine years.

Keywords: ARDS (acute respiratory distress syndrome), MIS-C (multisystem inflammatory syndrome in children), molecular mimicry, cross-reactivity,

Th lymphocytes (T helper lymphocytes), TC lymphocytes (cytotoxic T lymphocytes), TS lymphocytes (suppressor T lymphocytes), Treg lymphocytes (regulatory T lymphocytes), macrophages (Mf), monocytes, basophils, lymphatic tissue associated to the bronchial mucosa (BALT), monoclonal antibodies, cyclophosphamide (Cy).

\section{BACKGROUND}

Som ome assumptions support the theory of the "innocent witness", in which the hyper-activated lymphocytes (Th, especially Th1 and Th17), coordinating the other elements of the non-specific immune system, can no longer control the magnitude of the immune response, in the attempt to eliminate the virus and fatally damage the uninfected surrounding cells.

The essential parameter of this "cytokine storm" is the excessive activation of macrophages, with an increase of pro-inflammatory cytokines (IL-6, IL-12, interferon, TNF-alpha), to which there the factors issued by the mastocyte and neutrophil are added, the inflammation being supported and doubled by the activation and proliferation of the cells of the specific immune system (Th and TC).

The described hyperegic inflammatory phenomenon is also noticed under various cellular and humoral aspects in other severe viral or bacterial respiratory infections, in which there is a favorable response to at least one of the existing anti-inflammatory or immuno-depressive therapies (for instance, glucocorticoid administration in pleurisy or tuberculous meningitis), compared to the inflammation associated to Sars-CoV-2 infection, which manifests an extreme rigidity to all immunomodulatory therapies.

In these conditions, we must see which is its complex mechanism and whether the reaction involves the intervention of several antigenic determinants, as in the case of the toxic-septic shock from the genital infections with Staphylococcus in women during their menstrual period who wear tampons.

In COVID-19, the cross-reactivity between the viral epitopes and pulmonary tissue structures, which generates a severe pneumonia, could be doubled by a mechanism of cross-reactivity with the chemical antigens introduced in the body (gaseous or belonging to the intubation cannula) in certain patients. Normally, this should induce a phenomenon of immunologic tolerance (specific and active inhibition reaction of the immune response towards an endogenous or exogenous antigen); the new pathology related to chemical immunogenicity in the last years doubles the infectious one, which could explain the extremely difficult therapeutic approach.

In general, the gaseous oxygen is an exogenous molecule which has a total tolerance from the body (so, it functions as haptens). In a soluble 
state, in which it is bound to the hemoglobin as oxyhemoglobin, it becomes a self-structure and has immunologic tolerance. It is likely that in some adult patients with immunologic defect at the level of BALT, this hapten binds to the structure of a protein at the level of the respiratory mucosa and modifies its structure, obtaining immunogenicity and starting a hyperegic response. This is the main model of the intolerance reaction to chemical substances and medicines and it is the closest to the IV type of hypersensitivity reactions (Table 1 ).

During type IV hypersensitivity reactions, the following patterns can be differentiated:

- Jones Mote reaction: contact of the cutaneous tissue with soluble antigens, the main effectors being represented by mastocytes and basophils instead of macrophages; it is one of the mechanisms of contact rash - through chemical or physical agents, including radiations (sun rash), pressure, temperature (rash in case of cold and hot weather, where the mechanism is mainly humoral;

- contact hypersensitivity - it appears at the contact of the cutaneous tissue with incomplete antigens or haptens, usually chemical (metals, plastic materials, anesthetic drugs or antibiotics applied as ointments), which usually have a small molecular weight and a simple structure, and at the level of the epidermis are coupled with free proteins or belonging to the membrane of the epidermal cells, and from haptens they become complete antigens. In the inflammatory outbreak, Th lymphocytes sensitized through a previous contact (lymphocytes with memory) attract the main effectors, including specific antigen TC lymphocytes, macrophages, mastocytes and basophils;

- delayed classic hypersensitivity (tuberculin type): the prototype is represented by the intradermic-reaction at tuberculin - the reaction started through the inoculation of tuberculin, a substance extracted from Koch bacillus cultures; at the inoculation place, the sensitized Th lymphocytes recruit other cells, especially macrophages. The main protagonist of the reaction is represented by macrophage activated by $\mathrm{TH} 1$ lymphocyte (via IL-2) and macrophage profile cytokines (IL-1, TNF-alpha), IL-6 secreted by the endothelial cells activated by IL-1. Through these

TABLE 1. The main types of hypersensitivity reactions

\begin{tabular}{|l|l|l|l|}
\hline $\begin{array}{l}\text { Hypersensitivity } \\
\text { reactions }\end{array}$ & Mechanism & Examples & Response to medication \\
\hline Type I & $\begin{array}{l}\text { Medication Ig E } \\
\text { (reaginic) }\end{array}$ & $\begin{array}{l}\text { Allergy } \\
\text { Bronchial asthma } \\
\text { Anaphylactic shock }\end{array}$ & $\begin{array}{l}\text { Intense response to } \\
\text { corticotherapy }\end{array}$ \\
\hline Type II & $\begin{array}{l}\text { - mediated by antibodies } \\
\text { (cytotoxic-cytolytic) } \\
\text { - antigens associated to the } \\
\text { cell or matrix } \\
\text { - opsonic phagocytosis }\end{array}$ & $\begin{array}{l}\text { Goodpasture (respiratory and urinary } \\
\text { dysfunctions through antibodies anti } \\
\text { basal membrane) } \\
\text { Autoimmune hemolytic anemia } \\
\text { Post-transfusion hemolysis } \\
\text { Hemolytic disease of the newborn }\end{array}$ & $\begin{array}{l}\text { Response to corticotherapy. } \\
\text { immuno-depressive drugs } \\
\text { and monoclonal antibodies }\end{array}$ \\
\hline Type III & $\begin{array}{l}\text { Mediated by immune } \\
\text { complexes }\end{array}$ & $\begin{array}{l}\text { Prototype serum disease and Arthus } \\
\text { phenomenon. Collagenoses vasculitis } \\
\text { "farmer's lung", "bird breeders' lung" }\end{array}$ & $\begin{array}{l}\text { Response to corticotherapy. } \\
\text { immuno-depressive drugs } \\
\text { and monoclonal antibodies }\end{array}$ \\
\hline Type IV & $\begin{array}{l}\text { Th lymphocyte } \\
\text { Macrophage } \\
\text { Mastocyte }\end{array}$ & $\begin{array}{l}\text { Jones Mote reaction } \\
\text { Tuberculin reaction } \\
\text { Contact reaction } \\
\text { Granulomatous reaction }\end{array}$ & $\begin{array}{l}\text { Miastenia gravis } \\
\text { Antibodies anti-receptor of acetylcholine }\end{array}$ \\
Tym & $\begin{array}{l}\text { IgG or IgM antibodies } \\
\text { (modify the signalization) }\end{array}$ & $\begin{array}{l}\text { corticotherapy. immuno- } \\
\text { depressive drugs and } \\
\text { Plasmapheresis }\end{array}$ \\
\hline
\end{tabular}


IL-1 and TNF-alpha produced by the macrophages from the outbreak, the pro-coagulating properties of the local endothelia are augmented, with the stimulation of the pro-aggregating properties of the platelets;

- the granulomatous reaction, with the transformation of macrophages in epithelioid and multi-nucleated giant cells.

It results that COVID-19 infection is close to tuberculin hypersensitivity: the cytokine storm is similar and the protagonist is the macrophage activated by Th1 and mastocyte. This type of reaction is one of the mechanisms encountered in infections with intracellular germs and it is triggered by a part of the proteins of the Koch bacillus. In tuberculosis (primary or secondary infection), the global mechanism is much more complex and involves a major participation of several cellular mechanisms (Tc lymphocytes, NK cells and macrophages), with a massive discharge of cytokines of $\mathrm{T}$ and macrophage profile. In any high pathogenic infection, a major participation of the specific immune system, doubled by the non-specific one, is expected. However, in the COVID-19 infection, a paradox appears: the cytokine storm is predominantly macrophage and mastocytic, doubled by the activation of cells of the specific immune system. We cannot find an intense expression of the main antiviral effectors, including Tc lymphocytes and NK cells. Also, at the level of the humoral immunity, an atypia can be found: the IgM antibodies appear later and they are non-specific, opposite to usual viral infections; the antibodies used in the diagnosis are of $\lg$ type.

All these aspects suggest an additional involvement of certain chemical antigens that initiate hyperergia, with protagonists belonging to the non-specific immune system, as in the hypersensitivity induced by chemicals (contact dermatitis).

In COVID-19, the reaction is similar to contact dermatitis, but it develops at the level of the respiratory mucosa (BALT, which main resident cell is the siderophage) and can be triggered by a chemical or physical immunogen, most probable the hapten bound with a tissue protein. It is important that before these had tolerance, which theoretically means the possibility for the $\mathrm{TH}$ lymphocytes to return to normal. This seems also to be the case of the angioedema induced by IECA and sartans. A similar situation can be found in the adverse reactions to IECA and sartans; the angioedema, that probably involves an immunologic mechanism, sometimes appears after months or years of treatment, it lasts for a few days up to several months, then totally disappears and evolves in episodes, with long periods of pause. IECA as the sartans, are haptens, but, after a while, they might be noticed by the immune system, and, through an unknown mechanism, they sensitize a cellular line that secretes cytokines with vascular tropism, or sensitize the endothelial cells and modify the secretion of certain interleukins. Sometimes, the angioedema disappears under treatment, which also means the return to normal of the Th lymphocyte, with the recovery of the previous tolerance. The fact that tolerance appears and disappears in episodes shows that IECA and sartans are at limit (sometimes Th loses its tolerance but still institutes a minimum response, and subsequently, it spontaneous resumes the tolerance). Also, this particularity draws the attention over the fact that ECA2 receptors have been noticed for a while by the immune system, concomitantly with the complementary medication. This observation is sometimes used in the attempts of treatment through desensitization, which mainly aims to reduce the Th lymphocyte to the normal status.

A sort of demonstration for this purpose was performed in mechanically intubated patients, when bringing the oxygen at the BALT level led to the increase of the attention of the Th1 lymphocyte, which "reminded" of the previous selftolerance and accepted the intervention of the defensive mechanisms of immune response decrease through glucocorticoids.

In a similar manner, a patient with contact dermatitis at ointment with Sinedrol used for post-combustion wounds, who previously manifested a tolerance to Sinedrol and had accidentally administered it for several days after the onset of symptoms, developed tolerance to the ointment, with the disappearance of lesions under treatment. A similar situation can be found in the case of contact rash at clothes.

In gas gangrene, an infection with bacilli from the Clostridium genus, the toxic-septic shock frequently occurs; it is possible for an immunologic component to intervene through intolerance to the gas resulted from the bacterial fermentation of sugars, considering the severity of manifesta- 
tions and treatment resistance, which also includes an antibiotic treatment.

All reactions of this type have a difficult response to corticosteroids, except for cases when other mechanisms are also associated (type 1, 2 or 3).

This multiple treatment resistance results from the complexity of the mechanisms involved in the disruption of tolerance. There are two main mechanisms involved in the initiation of immunologic tolerance: 1) at central level, an intra-medullary and intra-thymus positive and negative selection occurs, with the selection of normal clones and deletion of the self-reactive ones, followed by the transfer of lymphocytes to the peripheral area; and 2) peripherally, the process is exclusively developed outside the thymus and it is based on antigen specific Ts cells, which determine the release of suppressor $\mathrm{T}$ factors with inhibitory effects; in case of local immunologic effects at the level of BALT, this extra-thymus self-tolerance is interrupted through a complex mechanism in which the main role is played by the contra-suppressor T lymphocytes, which inhibit the TS lymphocytes and activate the TH ones.

Usually, in all autoimmune diseases both types act, the central mechanism being predominant in the systemic diseases. In COVID-19 infection in children, it seems that the central mechanism is predominant, the response to glucocorticoids being better, while in adults the peripheral mechanism is predominant. Within it, the $T$ suppressor- $T$ counter-suppressor line is damaged, with the major cellular involvement of the macrophage and mastocyte. The reaction is controlled from the central level by Th lymphocytes, which is also defective (central and peripheral defect). It is important to analyze which of the TH subtypes is involved, causing such a high resistance to all therapies.

Usually, the macrophage reaction is coordinated by Th1 lymphocytes and the mastocytic one through Th2 lymphocytes, also involving a specific humoral response in antibodies, initially IgM and subsequently IgG.

The immunological profile of the COVID-19 infection involves: Th1 activation, with TC immobilization and the activation of the macrophage, with the profile cytokines (IL-6, TNF-alpha, interferon); Th17 activation, which probably coordinates the macrophages with the main macro- phage mediators; and activation of Th2 lymphocytes, with the recruitment of B lymphocyte and mastocytes, and the release of mastocyte mediators.

These types of associated reactions are frequently found in the pathology, but they are characterized through an at least partial response to therapy, especially because of the involvement of prototype 1 (mastocyte and basophil).

In COVID-19, it seems that more inversions are produced: the peripheral response seems to be more aggressive, supported by macrophages and mastocytes and doubled by the humoral immunity coordinated by Th2, in which probably the non-specific IgM antibodies are addressed to the hapten-carrier complex, and most of the specific antibodies are addressed to the virus. In these conditions, it seems that a part of the aggressive autoimmune response is supported by the TH2 lymphocytes (which also coordinate the mastocytes).

The Th1 lymphocytes primarily handle the antiviral defense (more through Tc and NK). The anti-chemical line seems to be predominantly supported by macrophages and their mediators, mastocytes and basophils, which should determine an at least partial response to corticotherapy. This line could be led by Th17 lymphocytes, which manifest oxygen intolerance. The Th1 lymphocyte, which is the main coordinator, had to lead a strong offensive reaction against a virus in parallel with an immuno-depression reaction to a chemical agent, and in certain persons it succeeds.

However, in patients with genetic defects it is possible that, besides the defect from Th17, a Th1 defect is also associated, which is initially involved in the anti-infectious defense, so it can no longer coordinate a braking reaction together with Ts of the anti-chemical immunologic response, as it would be expected. This means that Th17 lymphocyte has established an intolerance to the hapten-carrier complex, while Th1 lymphocyte has two variants: if it established intolerance, it triggers a rejection reaction; or, if it established tolerance - considering that it is stronger than Th17, it might accept the new variant of oxygen (oxyhemoglobin) also as self, considering the fact that it is the leader and it makes the major decisions. In these conditions, it is created a nonconformity between Th1 and Th17, which is rarely found in the autoimmune disea- 
ses. This is the only way in which the total lack of response to the treatment can be explained.

In general, the Th subsets concord, so that if they have instituted an activation command to a certain antigen, they mutually also accept an immunosuppressive therapeutic intervention, with a satisfactory response.

Only if Th1 and Th2 are uncompliant, in the sense that Th1 has instituted tolerance (which is very probable, considering the fact that oxygen is the antigen, including the one from inhaled air) and Th2, being defective, instituted non-tolerance, the response to the immunosuppressive therapy is blocked by Th1, which does not consider opportune the intervention in the conditions in which it has a severe infectious reaction. This means that the defect can also be found at the Th1 level, but backwards, it institutes tolerance too easily and fails to notice that Th17 has a defect: it hardly institutes tolerance and fails to listen to the Th1 commands.

A little girl has instituted an anaphylactic shock at Ampicillin given by injection in a hospital setting and she could not be saved despite all resuscitation measures used in the intensive care unit. Non-responsiveness to therapy could also be explained through a central non-compliance at the $\mathrm{TH} 1-\mathrm{TH} 2$ level, in which the shock reaction of IgE mediation was led by Th2 lymphocytes (activators of B lymphocytes through IL4, with the degranulation of mastocytes and basophils). Usually, the reaction takes place with the approval of Th1 lymphocytes, but this might have been a particular case in which Th1 has instituted tolerance to Ampicillin, while Th2 issued a reverse command, which led to the blocking of medication by Th1.

It is possible that a similar mechanism, with discrepancies between the Th subsets, is involved in other autoimmune diseases which are resistant to corticoids, such as erythematous lupus. These might be the cases reserved to plasmapheresis. In these conditions, the classical plasmapheresis could be tried in the inflammation associated to COVID-19.

\section{The cross-reactivity mechanism}

In COVID-19, the hapten can interact with a soluble protein or from the level of the cellular membrane. This could also be from the level of a receptor - for example, RECA2. An argument for this purpose would be the fact that the administration of non-neutralizing monoclonal antibodies (except for the RBD subunit of S protein) sometimes provides disease improvement. This means that this binding pushes away the structure.

Hapten-ECA receptors (carriers) has crossreactivity (large similarities) with the structure, and protein S-ECA receptors become non-neutralizing antibodies - protein S-ECA receptors, thus lowering the cross-reactivity with oxygen, which is one of the desiderates.

The administration of neutralizing antibodies induces blockage reactions such as neutralizing antibodies - protein S, in an attempt to decrease of pathogenicity. It can only be done in the low and medium forms, in which cross-reactivity seems to be absent (patients without respiratory assistance). This means that, in the form with cross-reactivity, these accentuate the inflammation. In this formula, more ECA receptors remain free, which means that they are involved in immunogenicity. They were also in the attention of the immune system in patients using IECA or sartans, so it seems they are prone to abnormalities. In these conditions, the complex medicine-ECA receptors does not seem to be the most adequate approach for the decrease of cross-reactivity, because the complexes of this type are for several years in the attention of the immune system as uncompliant. It is possible that the blocking of these receptors with monoclonal antibodies removes more hapten-ECA receptors complexes. It could be associated with the therapy with non-neutralizing monoclonal antibodies in order to decrease the cross-reactivity as much as possible.

The blocking of these receptors with IECA brought no benefits, meaning that the immunogenicity was not lowered.

Some specialists asked themselves if the virus acted directly on hemoglobin, producing changes at its level and, implicitly, at the level of oxyhemoglobin; nevertheless, extracorporeal oxygenation is better tolerated than invasive ventilation, which strengthens the suspicion of involvement of one of the gaseous forms. The action seems to be through the autoreactive immune system, because it is the only one that can break the physiological tolerance to oxygen, hemoglobin or oxyhemoglobin (a situation also encountered in the case of the nocturnal paro- 
xysmal hemoglobinuria, where the own red blood cells become susceptible to the action of complement through a genetic defect).

The British study RECOVERY (2020) showed that treatment with Dexamethasone resulted in a reduction in mortality by $20 \%$ in patients with COVID-19 pneumonia who needed oxygen supplement and by $35 \%$ in those who were mechanically ventilated, with no consequences in patients without respiratory assistance. This partial response to therapy with corticosteroids, only when oxygen supplementation was associated, could be explained through the mobilization of a large number of inflammatory cells to oxygen supplements versus oxygen from the inhaled air in patients with genetic defect. On the other hand, the severe reaction appears especially during intubation, which proves that the major defect is at the level of BALT. The administration of oxygen through mask or extracorporeal support is better tolerated; oxygen through mask is administered with a certain pressure and so, the first contact is with the MALT of the oral cavity (the lymphoid tissue associated to mucosa).

This is probable more integer than BALT and it better induces tolerance of first antigenic contact; similarly, the tolerance induced in the blood by extracorporeal oxygenation seems to be more efficient, and so, the major defect in adults seems to be at the BALT level, through the peripheral interruption of acquired tolerance of T lymphocyte.

In this context, it might be useful to test the immuno-modulators of Levamisol or Isoprinosina type, in the idea to stimulate the local Ts with the decrease of amplitude of the inflammatory immune response. These were also tested in other infectious diseases with autoimmune component of organ (for instance, chronic hepatitis) but with no obvious benefit.

This is probably due to the fact that, in all autoimmune diseases, there is a mechanism of interruption of central tolerance (congenital) of lymphocytes through the absence of deletion of certain autoreactive clones, intra-thymus and intra-medullary, through mutations in the corresponding genes. These autoreactive clones are described, from a pathologic anatomy point of view, also in SARS-Cov-2 infection (pulmonary infiltrates with activated $\mathrm{T}$ lymphocytes, predominantly CD8, as in most of the autoimmune diseases, because Th CD4 are more resistant and more difficult to be disordered). This is why the cancellation of these central autoreactive clones, which are especially Tc CD8+ autoreactive, represents the major desiderate in all autoimmune diseases. In any disorder, it seems that there are also resistant Th CD4 lymphocytes, because otherwise, survival could not be possible without Th lymphocytes. This is why the ideal immunosuppressor should not affect the Th lymphocytes or it should affect them as low as possible.

As a proof, the calcineurin inhibitors (Cyclosporine, Tacrolimus) are the strongest immunosuppressive agents in vitro, mainly acting on Th, IL-2 and Tc. But practically, their use is limited because in vivo, probably some Th lymphocytes remained after apoptosis are activated as a response to a too strong immunosuppression. In other words, they probably act too aggressively on Th lymphocytes, which leads to its counteraction (especially Tacrolimus, which is 10-100 times stronger than Cyclosporine). If these immunomodulators are haptens and are not recognized in a first stage by the immune system, the Th lymphocytes still recognize them through the study of their effects.

On the other hand, immunosuppressive agents like glucocorticoids, which in vitro are considered weaker, in practice they continue to be ranked first among immunosuppressive therapies; usually, these do not lead to a lymphocyte apoptosis, but only to the inhibition of CD4 + lymphocyte progress in the marrow and lymph nodes. In a similar manner, Azathioprine predominantly influences lymphocyte proliferation without acting on the cells being in a state of rest, and lymphatic toxicity is more selective on the large lymphocytes, granulocytes and thrombocytes (adverse reactions, granulocytopenia, thrombocytopenia). The Th lymphocyte, which is a cell of small dimensions, seems to be more affected through the reduction of proliferation, and not through cytotoxicity; activated cells are more frequently affected, while the ones at rest survive and ensure immunity through the Th line, which determines the classification of Azathioprine through the most reliable immunosuppressive agents. However, viral activation, in some cases of treatment with Imuran, can be important; thus, some authors launched the idea to use a treatment with Cyclophosphamide. Th lymphocytes manifest an increased resistance to 
small and medium doses. This makes it one of the mod beneficial immuno-suppressors; its administration conserves the Th lymphocytes, so it can be frequently administered in oncology as an antimitotic agent, with the maintenance of a minimum Th lymphocyte activity.

Cortisone and Azathioprine weakly inhibit Th lymphocytes, without lymphatic toxicity, while Cyclosporine and Cyclophosphamide in high doses (used in oncology) are too strong and probably partially counteracted (in vivo), so that all four therapeutic agents have imposed the most in the practice of immunosuppressive agent usage, and the area can be also extended to oncology. Also, transplant needs the highest doses in the human pathology, because the receiver's immune system, which is generally integer, manifests resistance and rigidity, which involves the necessity to increase the dosage similarly to that given in oncology.

Based on these data, researchers have also experimentally used immunosuppressive agents as a therapy of association in infectious pathologies, with components of immunologic hyperactivation, and some authors have recently proposed the use of Cyclophosphamide in inflammation associated to COVID-19.

The literature quoted the case of a young patient with glomerulonephritis who was treated with Cyclophosphamide and was able to overcome COVID-19 (positive tests, "ground glass opacified" on CT examination:), probably because the administered drug enabled the reduction of severe pulmonary manifestations.

Another case of pulmonary abscess with Mycoplasma pneumoniae, in a 10-year-old patient from Japan who presented paraclinical markers of hypercytokinemia, received an adjuvant treatment with Cyclosporine.

Also many years ago, treatments with glucocorticoids or even strong immunosuppressive medicines such as Azathioprine were administered with beneficial effects in chronic hepatitis with B virus (Ag HBe-). Only after many years of use, the effect was reversed, a viral activation being reported, with the accentuation of infection severity, which led to its interruption. The history of glucocorticoids might be repeated in patients with COVID-19, and these can be used as supportive treatment, under careful infectious and immunologic supervision, until signs of inefficiency or danger appear.

\section{Clinical particularities}

Some authors differentiate two types of viruses: with low pathogenicity and with high pathogenicity (h COVS), respectively, but genetic determinism also seems to be important; it is probable that patients with severe forms have a genetic defect in the increase of expression of genes encoding the R-ACE2 receptor, and also in the expression of certain tissue structures that intercross various viral epitopes. These epitopes do not necessarily belong to the major antigen determinants class, including spike (S) protein, RBD domain or other $\mathrm{S}$ domains; they can also belong to other epitopes borne by the virus, which do not have criteria of high pathogenicity as the $S$ protein, but they have criteria of immunogenicity. For this purpose, some studies show that some non-neutralizing monoclonal antibodies directed to these epitopes can lead to disease improvements.

According to the "Manual of Differential Diagnosis" (2016, R. Taylor), "dyspnea is a subjective experience of breathing discomfort, consisting of different qualities that vary in intensity"; thus, in theory, we could also consider the psychical, neurologic and metabolic and gaseous components.

From a clinical point of view, patients most frequently describe the sensation of suffocation that can also be found in medium and low forms of pneumonia, which is less usual, this symptom usually belonging to critical pneumonias, bronchial asthma and dyspnea. This makes us think to the gaseous components - hypoxemia/hypercapnia. Hypoxemia is well tolerated, in the sense that patients developed an adaptive mechanism consisting of a sort of resistance to oxygenic eviction, death being caused through marked hypoxemia, sometimes in the absence of severe pulmonary tissue lesions (necrotic).

In COVID-19, "happy hypoxemia" - which is also encountered in other disorders with chronic hypoxemia (intra-pulmonary shunts through arterial-venous malformations, left-right cardiac shunts, atelectasis) - seems to be a mechanism instituted through the neuro-hormonal, chemical, physical and pressure modifications of the main blood gases, in concordance with the decision of the immune system to reduce exposure to the immunogenic forms of oxygen and to resist to its low concentrations. 
In these conditions, there appears the paradoxical situation in which patients need oxygen but cannot tolerate it well. The decision of non-invasive administration seems to be the most beneficial solution; it remains to be seen if extracorporeal or mask administration is better tolerated, with a certain pressure, so that the first contact and the initiation of immunologic tolerance to be performed by the MALT of the nasal cavity (NALT) and oropharyngeal cavity.

Conflicts of interest: none declared. Financial support: none declared.

\section{References}

1. Bara C. Esential de imunologie, Editura ALL, 2002.

2. Carasevici E, Dumitriu I, Cianga C, Cianga $P$, Zugun-Eloae $F$. Imunologie, Universitatea de Medicina și Farmacie Gr. T. Popa, Iasi, 1999.

3. Channappansvor, Perman SF. Pathogenic human coronavirus ifections: causes and conse quences of cytokine storm and immunopathology. Semin Immunopathol 2017;39:529-539.

4. Codreanu C, Ionescu R, Predeteanu D, et al. Recomandări SRR: Managementul pacientilor cu boli reumatice în contextul COVID-19.

Viața Medicala 26, 3 iulie 2020.

5. Cojocaru M. Autoimunitatea în schizofrenie. Viața Medicala 20, 20 mai 2011.

6. Cojocaru M. Autoanticorpii și boala Alzheimer. Viața Medicala 51, 18 decembrie 2009.

7. Cristea V, Costin N, Crisan M, Olinescu A. Imunologie clinică, Ed. Casa cărții de știință, Cluj-Napoca, 1999.

8. Dejica D. Tratat de imunologie clinică. Ed. Dacia, Cluj-Napoca, 1997.

9. Dobrescu D, Dobrescu L, Negres S, McKinnon R. Memomed. Literatura Universitară, București, 2019.

10. Felsenstein S, Herbert JA, McNamara PS, Hedrich CM. COVID-19: Immunology and tratment options. Clin Immunol 2020;215:108448. doi: 10.1016/y.clim.2020.108448.

11. Gologan R. Manifestari autoimune asociate bolii.

Viata Medicala 37, 18 septembrie 2020 .
12. Gologan R. Noi aspecte privind infectia COVID-19. Coagulopatia-un comportament atipic. Viața Medicala 37, 18 septembrie 2020.

13. Ghioca C. Anticorpii Ig G COVID-19, mai probabil după 14 zile de simptomatologie. Viața Medicala 27, 10 iulie 2020.

14. Hughes E, Scurr M, Campbell E, et al. T-cell modulation by cyclophosphamide for tumour therapy. Immunology 2018;154:62-68.

15. Ionescu F. Vaccinuri candidate pentru COVID-19. Viața Medicala 23, 12 iunie 2020.

16. Perețianu $D$, Saragea MM. Imunologia în teoria și practica medicinei, Vol. II, Ed. All, 1998.

17. Popescu I Gr. Alergologie: fiziopatologie, diagnostic, tratament. Ed. All, 1998.

18. Poulsen NN, von Brunn A, Hornum M, Jensen MB. Cyclosporine and COVID-19: Risk or Favorable? Am J Transplant 2020;20:2975-2982.

19. Revannasiddaiah S, Kumar Devadas $S$, Palassery R, et al. A potential role for cyclophosphamide in the mitigation of acute respiratory distress syndrome among patients with SARS-CoV-2. Med Hypotheses 2020;144:109850. doi: 10.1016/j.mehy.2020.109850. Epub 2020 May 23.

20. Restian A. Marile dileme ale pandemiei de COVID-19.

Viața Medicala 32, 14 Aug 2020.

21. Restian A. Legătura dintre SARS-CoV-2 și bolile asociate.

Viața Medicala 25, 26 iunie 2020.
22. Rizescu BR. Agenda medicală ' 98 , Ed. Medicală, București, 1998.

23. Schoot TS, Kerckhoffs APM, Hilbrands LB, van Marum RJ. Immunosupppresive Drugs and COVID-19: A Review.

Front Pharmacol 2020;11:1333. doi: 10.3389/fphar.2020.01333.

24. Scurr M, Pembroke T, Bloom A, et al. Low-Dose Cyclophosphamide Induces Antitumor T-Cell Responses, which Associate with Survival în Metastatic Colorectal Cancer.

Clin Cancer Res 2017;23:6771-6780.

25. Simache A. Dexametazona, promițătoare în tratamentul COVID-19.

Viața Medicala 25-26, iunie 2020.

26. Simache A. Recunoasterea sindromului inflamator multisistemic, vitala pentru copiii cu COVID-19. Viața Medicala 37, 18 septembrie 2020.

27. Stroescu V, Chira C. Ignat $P$, et al. Agenda medicală, București, 1994.

28. Taylor R, Paulman PM, Paulman AA, et al. Manual de diagnostic diferential, Editura ALL, 201.

29. Udristioiu A. Ttratamentul cu anticorpi plasmatici anti SARS CoV 2, speranța în tratamentul COVID -19. Viața Medicala 31, 7 Aug 2020.

30. Voiculescu C, Pătrășcanu A, Voiculescu M, et al.

Noțiuni de imunologie și imunopatologie, Ed. Academiei Române, 1999.

31. Wooding DJ, Bach H. Treatment of COVID-19 with convalescent plasma: lessons from past coronavirus outbreaks. Clin Microbiol Infect 2020;26:1436-1446. 